\title{
Takotsubo cardiomyopathy presenting as pulseless electrical activity
}

\author{
Muhammad Faisal Khilji, Muhammad Mujtaba Shaikh
}

\begin{abstract}
Introduction: Takotsubo cardiomyopathy (TCM) is a rare condition, clinically presenting as myocardial infarction with normal coronaries and characterized by reversible apical ballooning of the left ventricle. Case Report: We present a case of a 40-year-old female presenting to the Emergency department (ED) of a tertiary care hospital after she collapsed suddenly and became unresponsive at the triage. She was having central chest pain before her collapse. Immediate Cardiopulmonary Resuscitation (CPR) was provided. Her rhythm was pulseless electrical activity (PEA) during the CPR. After two cycles of CPR she achieved ROSC (Return of Spontaneous Circulation) with electrocardiograph (ECG) showing ST elevation in lateral and inferior lead. She was taken to the catheterization laboratory immediately where her coronary arteries were found normal on coronary angiography with left ventricular apical hypokinesis in the shape of takotsubo (a Japanese octopus trapping fishing pot). Patient was discharged after one week of uneventful hospital stay. Her subsequent echocardiography after two months showed
\end{abstract}

Muhammad Faisal Khilji ${ }^{1}$, Muhammad Mujtaba Shaikh ${ }^{2}$

Affiliations: ${ }^{1}$ Sultan Qaboos University Hospital, Specialist, Emergency Medicine, P. O. Box 38, P.C. 123, AL-Khod, Muscat, Sultanate of Oman; ${ }^{2}$ Sultan Qaboos University Hospital, Senior Specialist, Department of Medicine(Cardiology), P. O. Box 38, P.C. 123, AL-Khod, Muscat, Sultanate of Oman.

Corresponding Author: Muhammad Faisal Khilji, Sultan Qaboos University Hospital, Specialist, Emergency Medicine, P. O. Box 38, P.C. 123, AL-Khod, Muscat, Sultanate of Oman; Email: faisalkhilji@yahoo.com

Received: 19 April 2018

Accepted: 21 May 2018

Published: 12 June 2018 almost complete recovery of left ventricular function proving it to be a case of Takotsubo cardiomyopathy. Conclusion: TCM should be suspected in all females with acute myocardial infarction.

Keywords: Chest pain, Coronary angiography, Myocardial infarction, Takotsubo cardiomyopathy

\section{How to cite this article}

Khilji MF, Shaikh MM. Takotsubo cardiomyopathy presenting as pulseless electrical activity. Int J Case Rep Images 2018;9:100921Z01MK2018.

Article ID: 100921Zo1MK2018

$* * * * * * * * *$

doi: 10.5348/100921Zo1MK2018CR

\section{INTRODUCTION}

Takotsubo cardiomyopathy was first described in 1990 by Sato et al in Japan [1-7]. It presents as clinical picture of myocardial infarction characterized by apical ballooning of left ventricle. Different terms used for this condition are stress-induced cardiomyopathy, ampulla cardiomyopathy, broken heart syndrome and transient left ventricular apical ballooning syndrome. Takotsubo is a Japanese word meaning "octopus pot", which is a wide based narrow neck pot to catch octopus [1]. In TCM left ventricle appears like this pot. Clinical presentation of TCM is usually acute chest pain with electrocardiograph showing ST elevation, mainly in anterior leads. Coronary angiography shows normal coronary vessels with ballooning of left ventricle apex resolving in subsequent weeks. Emotional and physical stress has relationship with the development of this condition [8]. It is important to consider this diagnosis in patients presenting as acute 


\section{EDORIUM Journals}

coronary syndrome (ACS) in Emergency Department. This case report highlights a case of a 40-year-old lady that presented to the emergency department of a tertiary care hospital with cardiac arrest of PEA and later found to have TCM. This reported is the first case report of TCM presenting as PEA.

\section{CASE REPORT}

We present a case of a 40-year-old female, with no atherogenic risk factors, presented to the ED of a tertiary care hospital. She was having central chest pain for the last one day without any emotional or physical trigger. Upon arrival to ED, she collapsed suddenly and became unresponsive, at the triage. There was no respiratory activity and central pulses were absent. Basic life support was started immediately and patient shifted to resuscitation area where advanced life support with cardiopulmonary resuscitation (CPR) was provided. Her cardiac rhythm on monitor was pulseless electrical activity (PEA). Blood glucose was normal. Return of spontaneous circulation (ROSC) with return of conscious level was achieved after two cycles of CPR. Upon ROSC her BP was 141/112 mmHg with regular heart rate of 140/min. ECG showed ST elevation in inferior and lateral leads (Figure 1). Bedside echo showed apical hypokinesia without any evidence of pericardial effusion, right ventricular strain or aortic dissection. Impression of inferio -lateral myocardial infarction was made. Oral Aspirin 300 mg, Clopedogrel 6oomg and intravenous Heparin 5000 IU (international units) were given. Cardiology consult was generated and patient was taken to catheterization laboratory. Her coronary arteries were normal in angiography (Figure 2A, B). Left ventriculography showed hyper dynamic basal myocardial segments with apical akinesis, in the shape of a "takotsubo" with estimated left ventricular ejection fraction of 25\% (Figure 2C and D). During angiography patient went into cardiac arrest again but ROSC was achieved after three minutes of CPR. Temporary pacing wire was left as backup after angiography, at rate of 8o/ min, as patient went into junctional rhythm post ROSC. Full blood count, renal functions and electrolytes were normal. Serial troponin -I reached a peak of $30 \mu \mathrm{g} / \mathrm{ml}$ and then gradually became normal. Patient later recovered uneventfully and was discharged after one week of hospital stay. Her follow up echocardiography after two months showed near normal improvement in her left ventricular function with ejection fraction of $40 \%$ to $45 \%$ proving it to be a case of Takotsubo cardiomyopathy.

\section{DISCUSSION}

TCM is a condition characterized by reversible systolic dysfunction of left ventricle with apical hypokinesia [9]. It can present from first to ninth decade of life and constitutes about $1 \%$ to $2 \%$ of patients presenting with ACS

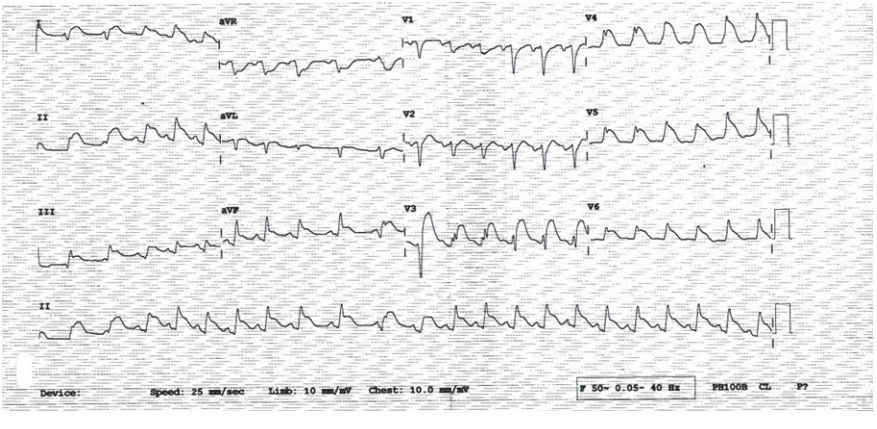

Figure 1: ECG showing ST elevation in anterior and inferior leads.

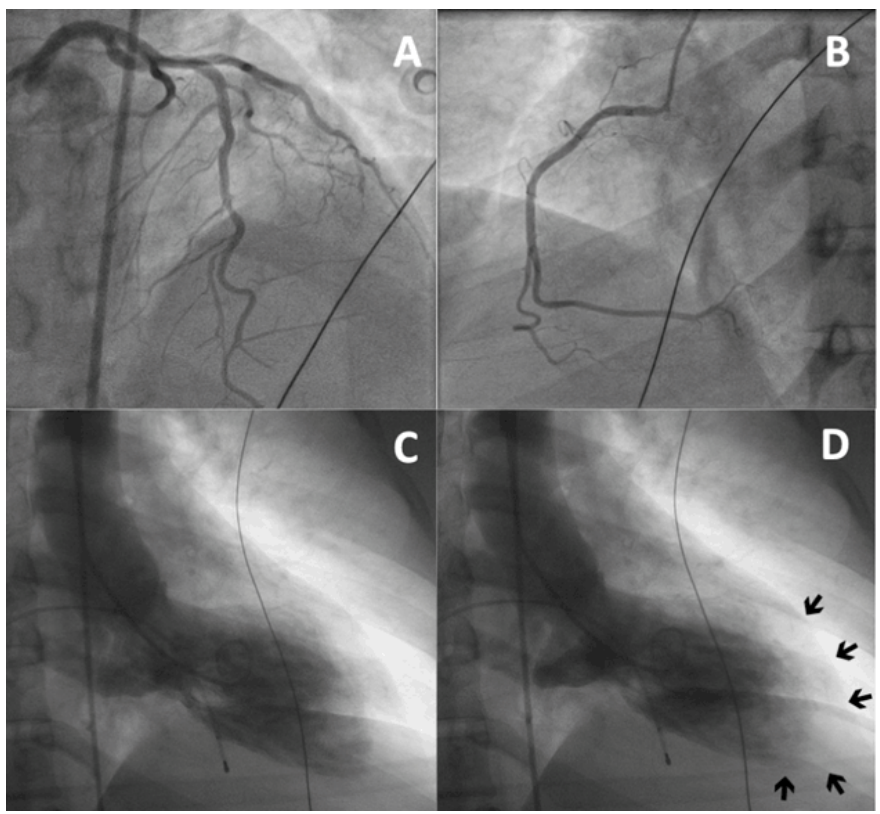

Figure 2: Emergency cardiac catheterization showing normal left (A) and right (B) coronary arteries. Left ventriculography with diastolic phase (C) and systolic phase showing apical akinesis, in the configuration of a "tako-tsubo" (D).

$[10,11]$. Most of the TCM patients are post-menopausal females with less than $10 \%$ of the cases are males. The first large TCM Japanese series showed 76 females, 12 male patients with median age of $67 \pm 13$ years [11]. Chest pain was the most common presenting symptom, present in $70 \%$ to $90 \%$ of the patients as in our case also. Other symptoms were shortness of breath and pulmonary edema. Cardiogenic shock, ventricular arrhythmias and cardiac arrest are rare presentations [11]. Our case presented as cardiac arrest. Not always but usually a psychological, emotional or physical trigger or any of their combinations are triggering factor [10]. Anxiety or pain related to medical procedure, breaking of bad news, or sudden surprises are few reported precipitants of TCM [8]. Akinesia of apical or mid ventricular area is typically present but other wall motion abnormalities could also be seen. TCM of only mid ventricular area without apical involvement is also reported [12]. Although several cases were reported with this disease but no case has been 


\section{EDORIUM Journals}

reported presenting to ED as pulse less electrical activity (PEA), requiring cardiopulmonary resuscitation (CPR). There is no consensus but modified Mayo criteria, is used for the diagnosis, which includes Transient dyskinesia, hypokinesia or akinesia of left ventricle with or without apical involvement usually associated with physical or emotional trigger. Coronary angiography shows normal vessels. New ECG abnormalities, ST segment elevation with or without $\mathrm{T}$ wave inversion, or slightly elevated troponins. No evidence of pheochromocytoma or myocarditis [13]. For precise differentiation between takotsubo myocarditis and myocardial infarction, magnetic resonance imaging (MRI) and myocardial histopathological studies can be used [14]. Takotsubo cardiomyopathy has no specific treatment, however pulmonary edema is treated with upright position, oxygen, diuretics and nitrates. Non-invasive ventilation can be used according to the condition [15]. Intraaortic balloon pump is used in cases of shock. Inotropes are generally not indicated. Arrhythmias due to QT prolongation can be treated with magnesium sulphate. Use of aspirin and heparin is controversial. Although left ventricular rupture has been reported secondary to takotsubo cardiomyopathy, the prognosis is generally good. The main complications are heart failure and pulmonary edema.

\section{CONCLUSION}

Although well known in cardiology, the condition should be considered in patients presenting to ED as myocardial infarction or in cardiac arrest, especially in females.

\section{REFERENCES}

1. Sato $H$, Tateishi $H$, Dote $K$, Uchida $T$, Ishihara $M$. Takotsubo like left ventricular dysfunction due to multivesselcoronary spasm. In: Kodama K, Haze K, Hori M, editors. Clinical Aspect of Myocardial Injury: From Ischemia to Heart Failure. Tokyo, Japan: Kagakuhyoronsha Publishing Co; 1990. p. 56-64.

2. Bybee KA, Prasad A. Stress-related cardiomyopathy syndromes. Circulation 2008 Jul 22;118(4):397-409.

3. Akashi YJ, Goldstein DS, Barbaro G, Ueyama T. Takotsubo cardiomyopathy: A new form of acute, reversible heart failure. Circulation 2008 Dec 16;118(25):2754-62.

4. Camara MAC, Dalia CG, Gomez FH. Sindrome de Takotsubo, reporte de dos casos y revision de la literature. Rev Assoc Mex Med Crity Ter Int 2012;26:51-5.

5. Redfors B, Shao Y, Lyon AR, Omerovic E. Diagnostic criteria for takotsubo syndrome: A call for consensus. Int J Cardiol 2014 Sep;176(1):274-6.

6. Sharkey SW, Windenburg DC, Lesser JR, et al. Natural history and expansive clinical profile of stress (tako-tsubo) cardiomyopathy. J Am Coll Cardiol 2010 Jan 26;55(4):333-41.
7. Templin C, Ghadri JR, Diekmann J, et al. Clinical features and outcomes of takotsubo (stress) cardiomyopathy. N Engl J Med 2015 Sep 3;373(10):929-38.

8. Sharkey SW, Lesser JR, Maron BJ. Cardiology patient page. Takotsubo (stress) cardiomyopathy. Circulation 2011 Nov 1;124(18):e46o-2.

9. Scantlebury DC, Prasad A. Diagnosis of takotsubo cardiomyopathy. Circ J 2014;78(9):2129-39.

10. Tsuchihashi K, Ueshima K, Uchida T, et al. Transient left ventricular apical ballooning without coronary artery stenosis: A novel heart syndrome mimicking acute myocardial infarction. Angina pectorismyocardial infarction investigations in Japan. J Am Coll Cardiol 2001 Jul;38(1):11-8.

11. Parodi G, Del Pace S, Carrabba N, et al. Incidence, clinical findings, and outcome of women with left ventricular apical ballooning syndrome. Am J Cardiol 2007 Jan 15;99(2):182-5.

12. Steen H, Merten C, Katus HA, Giannitsis E. Images in cardiovascular medicine. A rare form of midventricular Tako-Tsubo after emotional stress followed up with magnetic resonance imaging. Circulation 2006 Aug 15;114(7):e248.

13. Prasad A, Lerman A, Rihal CS. Apical ballooning syndrome (Tako-Tsubo or stress cardiomyopathy): A mimic of acute myocardial infarction. Am Heart J 2008;155:408-17.

14. Syed IS, Prasad A, Oh JK, et al. Apical ballooning syndrome or aborted acute myocardial infarction? Insights from cardiovascular magnetic resonance imaging. Int $\mathrm{J}$ Cardiovasc Imaging 2008 Dec;24(8):875-82.

15. Yoshioka T, Hashimoto A, Tsuchihashi $\mathrm{K}$, et al. Clinical implications of midventricular obstruction and intravenous propranolol use in transient left ventricular apical ballooning (Tako-tsubo cardiomyopathy). Am Heart J 2008 Mar;155(3):526. e1-7.

$* * * * * * * * *$

\section{Author Contributions}

Muhammad Faisal Khilji - Substantial contributions to conception and design, Acquisition of data, Drafting the article, Revising it critically for important intellectual content, Final approval of the version to be published Muhammad Mujtaba Shaikh - Substantial contributions to conception and design, Analysis and interpretation of data, Drafting the article, Final approval of the version to be published

\section{Guarantor of Submission}

The corresponding author is the guarantor of submission.

\section{Source of Support}

None

\section{Consent Statement}

Written informed consent was obtained from the patient for publication of this case report. 


\section{Conflict of Interest}

Authors declare no conflict of interest.

\section{Copyright}

(C) 2018 Muhammad Faisal Khilji et al. This article is distributed under the terms of Creative Commons
Attribution License which permits unrestricted use, distribution and reproduction in any medium provided the original author(s) and original publisher are properly credited. Please see the copyright policy on the journal website for more information.
Access full text article on other devices

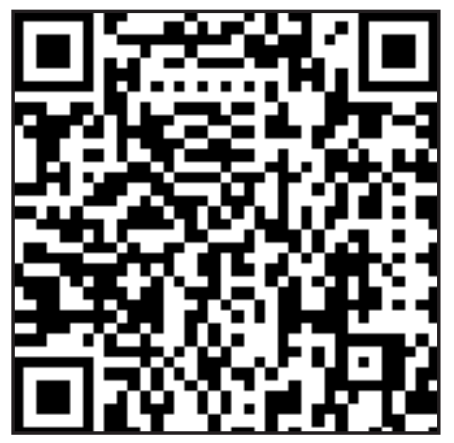

Access PDF of article on other devices

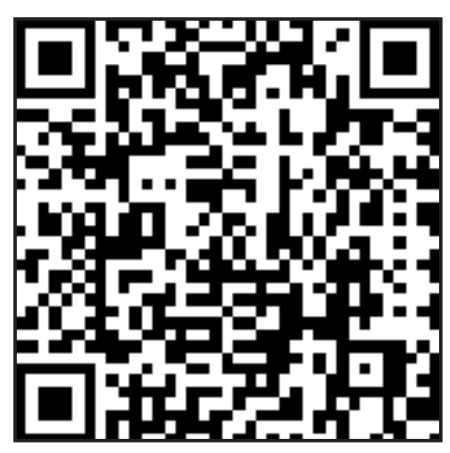

